\title{
NON DARCIAN APPROACH TO FLOW OF AN \\ INCOMPRESSIBLE VISCOUS FLUID BETWEEN TWO SEMI- INFINITE PARALLEL PLATES PARTIALLY FILLED WITH HIGHLY POROUS MEDIUM
}

\author{
Dr.Shiva Shanker K. \\ Assistant Professor,Dept of Mathematics \\ Kakatiya Institute of Technology \& Science, \\ Warangal, Telangana, India.
}

\section{ABSTRACT}

The aim of the present paper is to investigate the flow of an incompressible viscous fluid between two semi-infinite parallel plates. The space between the parallel plates is filled partially with highly porous medium. The flow will be two phase flow one in clear region and an other in porous region. The expressions for fluid velocities in both regions and flow rate are obtained sophisticatedly. The effect of permeability parameter on fluid velocities in both regions are investigated. The results are graphically represented.

Keywords : Porous medium, two phase flow, permeability parameter.

Corresponding Author: Dr.Shiva Shanker K.

\section{INTRODUCTION}

The study of flow through porous medium assumed importance because of the interesting applications in the diverse fields of science, Engineering and Technology. The practical applications are in the percolation of water through soil, extraction and filtration of oils from wells, the drainage of water, irrigation and sanitary engineering and also in the inter disciplinary fields such as biomedical engineering etc. The lung alveolar is an example that finds applications in an animal body. The classical Darcy's law Musakat [1] states that the pressure gradient pushes the fluid against the body forces exerted by the medium which can be expressed as

$$
\vec{V}=-\left(\frac{k}{\mu}\right) \nabla P
$$

The law gives good results in the situations when the flow is uni-directional or the flow is at low speed. In general, the specific discharge in the medium need not be always low. As the specific discharge increases, the convective forces get developed and the internal stress generates in the fluid due to its viscous nature and produces distortions in the velocity field. In the case of highly porous medium such as fiber glass, papus of dandelion the flow occurs even in the absence of the pressure gradient.

Modifications for the classical Darcy's law were considered by the Beavers and Joseph [2], Saffman [3] and others. A generalized Darcy's law propsed by Brinkmann [4] is given by

$$
O=-\nabla P-\left(\frac{\mu}{K}\right) \vec{v}+\mu \nabla^{2} \vec{v}
$$

where $\mu$ and $K$ are coefficients of viscosity of the fluid and permeability of the porous medium. The applications of flows through porous medium bears wide spread interest in 
Geophysics, biology and medicine. In many of these areas the flow consists of more than one phase, such type of flows find applications in the inter disciplinary fields such as bio-medical engineering etc., the flow of blood is one such application. The blood may be represented as Newtonian fluid and the flow of the blood is in two layered. Lightfoot [5], Shukla et al. [6] and Chaturani [7]. Bird et al. [8] found an exact solution for the laminar flow of two immiscible fluids between two parallel plates. Bhattacharya [9] discussed the flow of immiscible fluids between rigid plates with a time dependent pressure gradient. Vajravelu et al. [10] have discussed the effect of magnetic field on unsteady flow of two immiscible conducting fluids between two permeable beds. Transciet couette flow in a rotating non-Darcian porous medium parallel plate configuration is studied by Anwarbeg et al. [11] Kandryzakaria et al. [12] discussed magneto hydrodynamics instability of interfacial waves between two immiscible cylindrical fluids.

Earlier Narasimhacharyulu et al. [13] studied the problem of two phase fluid flow between parallel plates with porous lining and Narasimhacharyulu et al. [14] examined the flow of micropolar fluid between parallel plates coated with porous lining. Earlier Narasimhacharyulu et al.[16] studied the problem of two Phase flow of an incompressible viscous fluid between two semi-infinite parallel plates under transverse magnetic field,

In this present paper we are considering the fluid flow between two parallel plates, the space between the plates is partially filled with highly porous medium. There exists two regions one flow in clear region and other flow in porous region. The results are graphically represented.

\section{MATHEMATICAL FORMULATION OF THE PROBLEM}

The flow of an incompressible viscous liquid is considered between two semi infinite parallel plates given by $y= \pm h$. The space between the plates is filled with porous region of thickness ' $2 \delta$ '. The space between the two plates represents flow of fluid in two phases, one in clear region and other in porous region. The Coordinate system is taken such that $\mathrm{x}$-axis lies parallel to the length of the plates and $y$-axis perpendicular to the length of the plates. The fluid flows in the two regions under a constant pressure gradient.

$$
G=-\frac{\partial p}{\partial x}
$$

The velocity of the fluid $\vec{V}=(u, 0,0)$ satisfies the equation of continuity, the physical quantities depends on y only.

The equation of motion in the two regions is given by

$$
\begin{aligned}
& \frac{d^{2} u p}{d y^{2}} \quad \frac{u_{p}}{k}=\underline{G} \\
& \frac{d^{2} u c}{d y^{2}}=\underline{G} \\
& -\delta<y<\delta \\
& -h<y<-\delta \text { and } \delta<y<h
\end{aligned}
$$

Where $G=-\frac{\partial p}{\partial x}$ is a constant pressure gradient, in the direction, $v$ is coefficient of viscosity of the fluid, $\mathrm{k}$ is permeability of the porous medium. $u_{p}$ and $u_{c}$ are velocity of the fluid in the porous and clear region respectively using the following non-dimensional quantities.

$$
u^{*}=\frac{u h}{}, y^{*}=\frac{y}{h}, G^{*}=\frac{G h^{3}}{K}, \quad 2=\frac{h^{2}}{K} \ldots
$$


After removing *, the non-dimensional form of equation of motion is

$$
\begin{gathered}
\frac{d^{2} u_{c}}{d y^{2}}=-\frac{G}{v} ; \quad-1<y<-\frac{\delta}{h} \quad \text { and } \quad \frac{\delta}{h}<y<1 \\
\frac{d^{2} u p}{d y^{2}}-\alpha^{2} u p=-\frac{G}{v} ; \quad-\frac{\delta}{h}<y<\frac{\delta}{h} \quad \text { where } \alpha=\frac{h}{\sqrt{k}} \quad \ldots
\end{gathered}
$$

The boundary conditions are given by

$$
\left.\begin{array}{lll}
u_{c}=u_{p} & \text { at } & y= \pm \frac{\delta}{h} \\
u_{c}=0 & \text { at } & y= \pm 1
\end{array}\right\}
$$

\section{SOLUTION OF THE PROBLEM}

Solving the equations (2.4) and (2.5) employing boundary conditions (2.6) we get

$$
\begin{aligned}
& u_{c}=\frac{G}{2 v}\left(1-y^{2}\right) \\
& u_{p}=\frac{G}{2 v}\left(1-y^{2}\right)+\frac{G}{4 v} \alpha^{2}\left(1-\frac{\delta^{2}}{h^{2}}\right)\left(y^{2}-\frac{\delta^{2}}{h^{2}}\right) \\
& \text { Flow rate } Q=\int_{-1}^{1} u d y \\
& Q=\frac{2 G}{3 v}-\frac{G}{3 v} \alpha^{2}\left(1-\frac{\delta^{2}}{h^{2}}\right) \frac{\delta^{3}}{h^{3}}
\end{aligned}
$$

\section{CONCLUSION}

The flow of incompressible viscous liquid is studied between two semi-infinite parallel plates partially filled space with highly porous medium. The flow is a two phase flow one in clear medium other in porous region.

In Fig. 1 it is observed that, the effect of the permeability of the porous medium is to decrease velocity in the porous medium with increasing value of K.From Fig. 2 it is observed that increasing values of permeability parameter the values of flow rate are decreasing and also thickness of the porous medium is increasing, the flow rate decreasing.

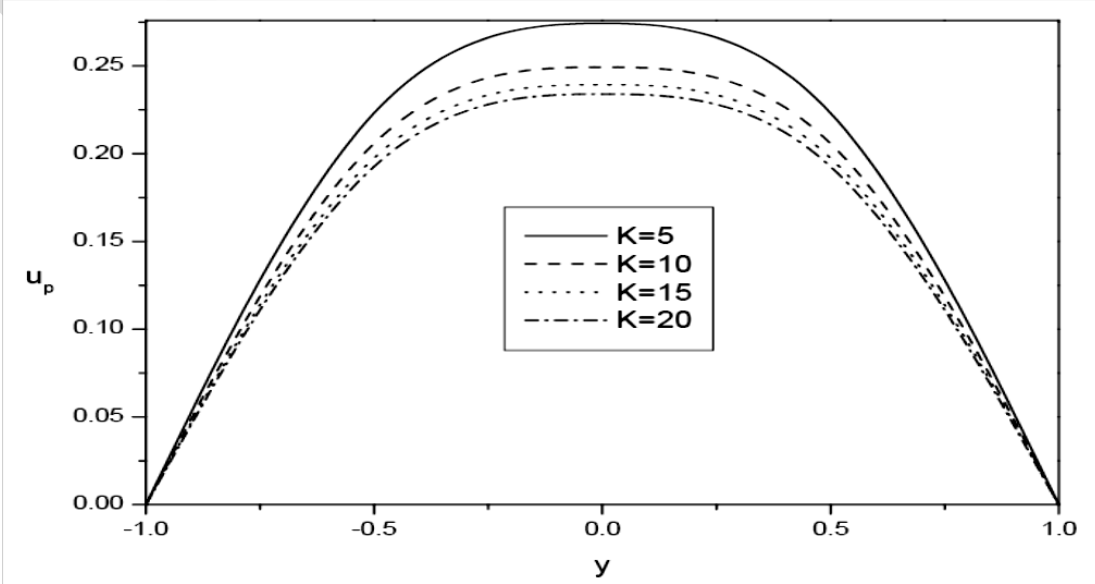

Fig. 1 : Variation of $\mathrm{u}_{\mathrm{p}}$ with permeability parameter $\mathrm{K}$ 
As viscosity of the fluid is increasing the velocity of the fluid is decreasing. Further it is also observed that as viscosity of the fluid is increasing, the flow rate of the fluid is deceasing.

The results of the problem have great importance to the petroleum engineer concerned with the movement of oil, gas and water through the reservoir of an oil or gas field. Beyond this, the results of present problem are widely applicable in soil mechanics, water purification, ceramic engineering and power metallurg

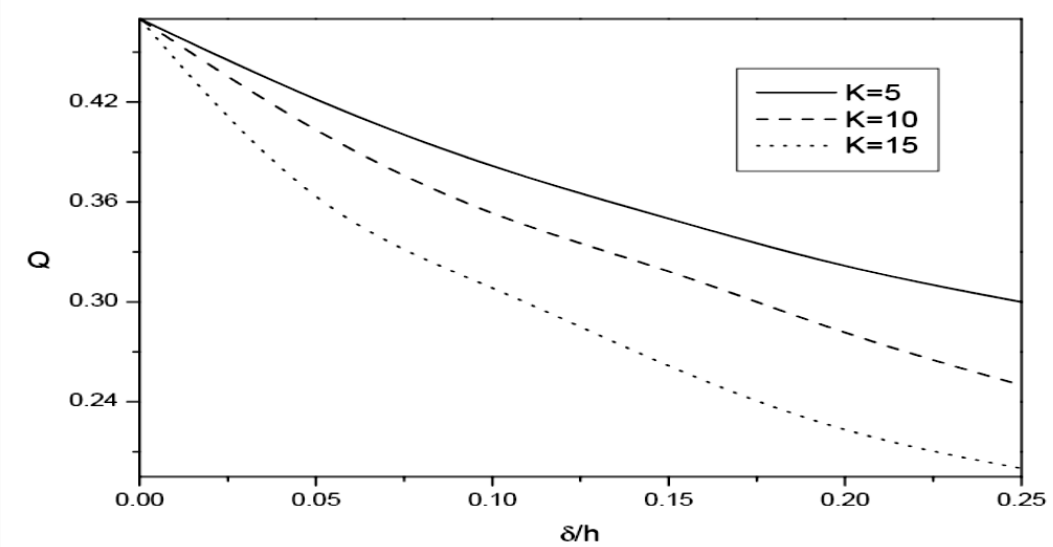

Fig. 2 : Flow rate for different values of permeability parameter $\mathrm{K}$

\section{REFERENCE}

1. Musakat, M. 1937. Flow of homogeneous fluid through porous medium, Mc Graw Hill Inc., New York, 1937.

2. Beavers S.G. and Joseph D.D. 1967. Boundary conditions at natural permeable wall, Int. J. of Fluid Mechanics, 30: 197-207.

3. Saffman P.G. 1971. On the boundary conditions at the surface of porous medium. Studies of Applied Maths, 50: 93-101.

4 Brinkman H.C. 1947. The calculation of viscous force exerted by a flowing fluid on a dense swerf of particles. Jl. of Applied Science Research 27,A1: 27-34.

5. Lightfoot, E.N. 1974. Transport phenomena in living system, John-Wiley and Sons, New York, 1974.

6. Shukla, J.B., Parihar, R.S. and Gupta, S.P., 1980. Effects of peripheral layer viscosity on blood flow through the artery with mild stenosis, Bulletin of Mathematical Biology, 42 : 797-805.

7. Chaturani, P. and Ponnalagar Samay R. 1985. A study of non-Newtonian aspects of blood flow through stenosed arteries and it's applications in arterial diseases. J. Biology, 22 : 521.

8. Bird, R.B., Stewart, W.E. and Lightfoot, E.N. 1960. Transport phenomena. John wiley and sons, Inc, New York.

9. Bhattacharya, 1968. The flow of immiscible fluids between rigid plates with a time dependent pressure gradient.

10. Vairavelu, K., Sreenadh, S. and Arunachalam, P.V. 1995. J. Math. Analysis and Aplications, 196 : 1105.

11. Anwar Beg, O. Takhar, H.S., Joaquin Zueco Sajid, A. Bhargava, R. 2008. Transient couette flow in a rotating non-Darcian porous medium parallel plate configuration. Acta Mechanica, 200 : 129.

12. Kadryzakaria, Magdy A. Sirwah and Ahmed Assaf. 2008. 
Magnetohydrodynamics instability of interfacial waves between two immiscible incompressible cylindrical fluids. Acta mechanica sinica. 24 : 497.

13. Narasimhacharyulu, V. 2007. Flow of a Newtonian fluid between two parallel plates with porous lining. Bulletin of pure and Applied Sciences. Vol. 26E(no. 1), 101-111.

14. Narasimha Charyulu, V. 2010. Laminar flow of an incompressible micropolar fluid between two parallel plates with porous lining. Int. J. of Appl. Math. And Mech. 6(14), 8192.

15. Sparrow, E.M and Cess, R.D., Trans. J. Appl. Mech. 29 (1962) 181.

16. Narasimha Charyulu, V. and Shiva shanker, K. Two Phase flow of an incompressible viscous fluid between two semi-infinite parallel plates under transverse magnetic field, International Journal of Computational and Applied Mathematics. Vol(8), 1(2013), PP. 25-35 